\title{
A continuum of attacks between tension-type headache and migraine: elaboration of a diagnostic score based on their clinical characteristics (Abstract)
}

\author{
Um continuum de crises entre cefaleia do tipo tensional e migrânea: elaboração \\ de um escore diagnóstico baseado nas suas características clínicas (Resumo)
}

\author{
Joaquim José de Souza Costa Neto \\ Universidade Federal de Pernambuco. Pós-graduação de Neuropsiquiatria e Ciências do Comportamento \\ (área de concentração: Neurologia). Ph.D. Thesis. Recife, 2011. Orientador: Marcelo Moraes Valença \\ Costa Neto JJS. A continuum of attacks between tension-type headache and migraine: elaboration of a \\ diagnostic score based on their clinical characteristics (Abstract). Headache Medicine. 201 1;2(2):75
}

Headaches have been described since time immemorial. The systematic use of the diagnostic criteria of the International Headache Society has contributed to homogenize the research results.

The objective of the present study is to analyze the epidemiological profile and the clinical characteristics of headaches diagnosed in a population selected for this reason so as to make possible the elaboration of a diagnostic score applicable to migraine and to tension-type headache. In a cross-sectional study there were evaluated 121 professionals, all university graduates comprising the corps of nurses of a university hospital. Ages of these professionals ranged from 27 to 63 years.

The methodological approach to the study can be summarised in the nosological classification of the existing headaches, in the classification and analysis of the clinical characteristics of the occasional attacks during the two months of observation, in the comparison of characteristics according to the nosology of the headache and, finally, to elaborate a diagnostic score based upon the quantitative aspects of the migraine attacks. There was a slightly higher prevalence of the tension type headache (71.9\% over migraine $(70.2 \%)$ in the test group, although there was a higher incidence of attacks of migraine $(47.0 \%)$ over attacks of tension-type headache (41.3\%) during the period of the study. The migraine attacks lasted from 4 to 72 hours (100\%), were predominantly bilateral (61.7\%), of pulsating type (54.1\%), were of moderate to severe intensity (93.2\%), were aggravated by routine physical activity (93.2\%) and always associated with accompanying symptoms (100\%). Generally the tension-type headache attacks lasted less than four hours (71.8\%), were bilateral (73.6\%) of heavy pressure-like character $(84.7 \%)$, were of mild to moderate intensity $(98.4 \%)$, were not aggravated by routine physical activity (66.7\%) and, habitually, not associated with accompanying symptoms (84.6\%). When varying a succession of natural numbers from zero to 100, this diagnostic score showed a common interval for both type of analysed attacks, thus characterising a continuum between the two.
One concludes that there exists a continuum of attacks for both tension-type headache and migraine whose differentiation can be ascertained through the application of a diagnostic score validated for this objective.

Correspondence

Dr. Joaquim José de Souza Costa Neto joaqcosta@yahoo.com.br 